tains the papers presented at the meeting with a brief record of the discussions and in addition $\mathrm{Mr}$. C. S. Orwin's paper "Agriculture and the War Stimulus", which owing to his absence was omitted from the programme. Mr. Headicar's paper "War. time Problems in Books and Binding" and MissE. M.R. Ditmas' paper "The Special Library in Time of War", together with Sir Richard Gregory's opening address "International Systems and Standards", were not included in the reprints issued in pamphlet form for use at the Conference. In addition to the summarized discussions, the pamphlet includes reports submitted from the National Central Library and the Citizens' Advice Bureau. The eighteenth annual conference of the Association will be held in the rooms of the Royal Society, Burlington House, London, W.1, on September 18 and 19. Particulars of the programme will be available later.

\section{Public Health in Honduras}

The January issue of the Boletin de la Oficina Sanitaria Panamericana contains an article on this subject by the Director of Public Health, Dr. P. H. Ordónez Días, who states that public health in Honduras is making notable progress since most of the people have become health conscious. Sanitary requirements, including health certificates for employees, have been enforced in public eating and drinking places and all others in which close contact with the public is required. A Biological Institute has recently been created for the preparation of serums and vaccines. The anti-venereal campaign has been intensified by the use of arsenical preparations. In spite of free distribution of anthelmintics, infestation by intestinal parasites is still prevalent. Only sporadic cases of malaria were observed. The milk station deals with a hundred children daily and distributes 163,332 bottles and 15,394 quarts of milk during the year, with the result that the child mortality in those attending the milk station was $68 \cdot 2$ as compared with $105 \cdot 6$ for the whole republic.

\section{Earthquakes in the Pacific}

The United States Coast and Geodetic Survey, in co-operation with Science Service and the Jesuit Seismological Association, has made a preliminary determination of the epicentres of three recent earthquakes in the Pacific Ocean. The first of these, on March 15, 1943, occurred at 4h. $47.9 \mathrm{~m}$. U.T. at an epicentre near latitude $10^{\circ} \mathrm{N}$,, longitude $142^{\circ} \mathrm{E}$., which is in the bed of the ocean to the north-east of Fuhaesu in the Caroline Islands. The second earthquake, also on March 15, ocourred at 22h. 59.2m. U.T. at an epicentre near latitude $14^{\circ} \mathrm{S}$., longitude $174^{\circ} \mathrm{W}$., which is in the bed of the ocean to the south-west of Savaii, Samon, and north-east of Fiji. This earthquake had a depth of focus in the neighbourhood of $300 \mathrm{~km}$. The third earthquake occurred on March 21 at approximately $20 \mathrm{~h}$. $35 \cdot 4 \mathrm{~m}$. U.T. from an epicentre near latitude $6^{\circ} \mathrm{S}$., longitude $146^{\circ} \mathrm{E}$., which is on land in the north-east of the island of New Guinea. The exact location is just south of Astrolabe Bay and the coast town of Dein. All these earthquakes occurred in well-known seismic regions, and all interpretations and calculations are tentative, the data being received from seismological observatories to Tucson, Sitka, Honolulu, Wellington, Pasadena, Fardham, Sydney, Buffalo, Brisbane and Apia.

\section{Announcements}

THE Zoological Society of London has arranged a course of popular lectures on natural history to be given at the Society's offices in Regent's Park, London. Admission is by ticket obtainable by post or at the Zoological Gardens on the day of the lecture. The first lecture will be given by Sir John Graham Kerr, who will speak on "A Naturalist in the Gran Chaco, South America", on July 28 at 3 p.m.

THE following appointments, promotions and transfers in the Colonial Service have recently been made: H. S. Darling, plant protection officer, Palestine; M. Landau, assistant veterinary officer, Palestine; A. J. Kerr (agricultural officer, Uganda), senior agricultural officer, Uganda; E. T. Fern (veterinary officer, Northern Rhodesia), deputy director of veterinary services, Northern Rhodesia; J. A. N. Hobday (chief veterinary officer, Bechuanaland), director of veterinary services, Northern Rhodesia.

THE Royal Society of Arts offers a prize under the Thomas Gray Memorial Trust, the objects of which are "The Advancement of the Science of Navigation and the Scientific and Educational interests of the British Mercantile Marine". The prize is of $£ 50$ and is open to any person of British or Allied nationality who may bring to the notice of the Society an invention, publication, diagram, etc., which in the opinion of the judges is considered to be an advancement in the science or practice of navigation, proposed or invented by himself during the period January 1 , 1938-December 31, 1943. Entries which have already been considered by the judges in the years 1938-42 are not eligible for further consideration unless they have since been materially modified. Competitors must forward their proofs of claim between October 1 and December 31, 1943, to the Acting Secretary, Royal Society of Arts, at the above address.

According to the Journal of the American Medical Association of March 6, the Foundation for the Study of Cycles, New York, a non-profit organization created to foster, promote and conduct scientific research on rhythmic and periodic fluctuations in any branch of science, announces the offer of a medal to the person who, during 1943, publishes the most outstanding book or paper on the subject. The Foundation is an outgrowth of the permanent committee set up in Matamek in Canada after the first International Conference of Biological Cycles. Besides the award of a medal, the Foundation makes awards for outstanding work in each branch of science. Further information can be obtained from Dr. Ellsworth Huntington, chairman of the Committee on Awards, Hendrie Hall, York University, New Haven, Conn.

The INDEX To VOLUME 151 oF "NATURE" (January to June 1943) will be published as a SUPPLEMENT to the issue for next week (JULY 31) 